\title{
О РЕЗУЛЬТАТАХ ЭКОНОМИЧЕСКОЙ ОПТИМИЗАЦИИ ДЕЯТЕЛЬНОСТИ МЕДИЦИНСКОЙ СЛУЖБЫ ФСИН РОССИИ
}

\author{
Р. У. Хабриев ${ }^{1}$, А. П. Суходолов ${ }^{2}$, Б. А. Спасенников ${ }^{3}$ \\ ${ }^{1}$ Национальный НИИ общественного здоровья им. Н. А. Семашко, Г. Москва, Российская Федерация \\ ${ }^{2}$ Байкальский государственный университет, г. Иркутск, Российская Федерация \\ ${ }^{3}$ НИИ Федеральной службы исполнения наказаний России, г. Москва, Российская Федерация
}

Информация о статье
Дата поступления
6 сентября 2017 г.
Дата принятия к печати
20 ноября 2017 г.
Дата онлайн-размещения
27 ноября 2017 г.
ключевые слова
Уголовно-исполнительная
система; общественное
здоровье; экономика
здравоохранения; медицинский
менеджмент; заболеваемость;
смертность

Информация о статье

\section{Аннотация}

В статье рассмотрены результаты работы медико-санитарной службы отечественной уголовно-исполнительной системы в 20152016 гг. В 2016 г. в итоге оптимизации расходов на деятельность медико-санитарной службы уголовно-исполнительной системы общее количество коек в стационарах медицинских организаций снизилось на 9,3 \% и составило 32,8 тыс. После сокращения расходов стали функционировать 673 медицинские части; 57 отдельных врачебных кабинетов; 143 фельдшерских здравпункта; 55 центров медицинской и социальной реабилитации; 136 больниц (в том числе 65 туберкулезных и 5 психиатрических); 13 домов ребенка; 72 центра санитарно-эпидемиологического надзора. В 2016 г. показатель смертности среди лиц, содержащихся под стражей или отбывающих наказание в виде лишения свободы, составил 533,3 случая на 100 тыс. чел., что на 9,8 \% ниже показателя прошлого года. Авторы сорормулировали предложения по дальнейшему совершенствованию нормативного обеспечения оптимизации расходов на деятельность уголовно-исполнительной системы.

\section{ON THE RESULTS OF ECONOMIC ACTIVITY OPTIMIZATION OF THE MEDICAL SERVICE OF THE FEDERAL PENITENTIARY SERVICE OF RUSSIA}

\author{
Ramil U. Khabriev ${ }^{1}$, Alexander P. Sukhodolov ${ }^{2}$, Boris A. Spasennikov ${ }^{3}$ \\ ${ }^{1}$ The N. A. Semashko National Research Institute for Public Health, Moscow, Russian Federation \\ ${ }^{2}$ Baikal State University, Irkutsk, Russian Federation \\ ${ }^{3}$ Research Institute of the Federal Penitentiary Service, Moscow, Russian Federation
}

\section{Article info}

Received

September 6, 2017

Accepted

November 20, 2017

Available online

November 27, 2017

\section{Keywords}

The penitentiary system; public health; economics of health; medical management; morbidity; mortality

\begin{abstract}
The article examines the results of work of the health service of the Russian penitentiary system in 2015-2016. In 2016, after optimizing the costs of the health service of the penitentiary system, the total number of beds in penitentiary hospitals decreased by $9,3 \%$ to 32800 . After spending cuts, there are: 673 medical units, 57 separate medical offices, 143 physician assistant's stations; 55 centers for medical and social rehabilitation; 136 hospitals (including 65 tuberculosis hospitals and 5 psychiatric hospitals); 13 infant orphanages; 72 centers of sanitary and epidemiological surveillance. The death rate in 2016 among people in custody or serving a sentence of imprisonment amounted to 533,3 per 100 thousand people, which is $9,8 \%$ lower than the previous year. The authors formulated proposals on further improving the regulatory support for optimizing the costs of the penal system.
\end{abstract}


В 2014-2016 гг. в рамках экономии бюджетных расходов была проведена оптимизация деятельности медико-санитарной службы ФСИН России. Однако оптимизация расходов не должна была привести к ухудшению результатов ее деятельности, что потребовало разработки и последовательного выполнения научно обоснованных мероприятий по повышению эфффективности деятельности службы.

Нами обобщены и изучены результаты деятельности медико-санитарной службы ФСИН России после оптимизации расходов на организацию медико-санитарного обеспечения подозреваемых, обвиняемых и осужденных'.

В 2016 г. общее количество коек в стационарах медицинских организаций уголовно-исполнительной системы (УИС) снизилось на 9,3 \% и составило 32,8 тыс. Были реорганизованы во врачебные и фельдшерские здравпункты 37 медицинских частей, что позволило привести структуру медицинских организаций в соответствие с объемами и условиями оказываемой медицинской помощи. На наш взгляд, такая оптимизация численности медицинских учреждений соответствует общим тенденциям российского здравоохранения. Сокращение коечного фонда связано с тем, что современные подходы к лечебно-диагностической помощи, развитие фрармакотерапии, иных современных технологий дают возможность оказывать больному амбулаторно помощь, которая ранее требовала пребывания в условиях стационара.

В настоящее время функционируют 673 медицинские части; 57 отдельных врачебных кабинетов; 143 фельдшерских здравпункта; 55 центров медицинской и социальной реабилитации; 136 больниц (в том числе 65 туберкулезных и 5 психиатрических); 13 домов ребенка УИС; 72 центра санитарно-эпидемиологического надзора.

В целях контроля проведения оптимизации деятельности медико-санитарной службы, согласно приказу ФСИН России от 27 мая 2016 г. № 384, была создана комиссия Федеральной службы исполнения наказаний по ведомственному контролю качества и безопасности медицинской деятельности. Прежде всего контролю подвергается выполнение мероприятий, предусмотренных комплексным планом медико-санитарной службы ФСИН России по снижению смертности в учреждениях УИС на 2015-2017 гг.

${ }^{1}$ Архив НИИ ФСИН России. 2017.
На 11 проведенных заседаниях комиссии рассмотрено 365 летальных исходов (от заболеваний) лиц, содержащихся в местах лишения свободы, которые умерли в 2016 г. По данным случаям, в том числе по выявленным нарушениям оказания медицинской помощи, были подготовлены шесть обзоров. В результате к дисциплинарной ответственности привлечено 44 сотрудника медико-санитарной службы УИС. Вместе с тем определено, что в подавляющем большинстве случаев оказание медицинской помощи заключенным соответствовало фредеральным стандартам.

Итогом проведенной работы, несмотря на сокращение расходов, стало улучшение важнейших медико-статистических показателей, которые являются объективными индикаторами деятельности медико-санитарной службы УИС.

В 2015 г. умерло 3828 лиц, содержащихся под стражей или отбывающих наказание в виде лишения свободы, а в 2016-м - 3408. В 2016 г. показатель смертности среди таких лиц составил 533,3 случая на 100 тыс. чел., что на 9,8 \% ниже показателя смертности прошлого года (589,3 случая на 100 тыс. чел.). Этот показатель можно считать наиболее важным среди всех полученных результатов оптимизации деятельности медико-санитарной службы.

От заболеваний сердечно-сосудистой системы в 2015 г. умерло 793 чел., в 2016-м - 763. Отмечается снижение показателя смертности на 3,8 \%, т. е. с 122,2 до 119,4 случая на 100 тыс. чел. По мнению Всемирной организации здравоохранения, Министерства здравоохранения России, снижение смертности от заболеваний сердечно-сосудистой системы - важнейший показатель лечебно-профрилактической деятельности.

Туберкулез всегда был актуальной проблемой для отечественной пенитенциарной службы. Число умерших от туберкулеза в учреждениях УИС в указанный период снизилось на 54,5\%, т. е. с 244 до 111 чел. Показатель смертности в перерасчете на 100 тыс. чел. снизился на 53,8 \% (с 37,6 до 17,4 случая на 100 тыс. чел.).

В 2016 г. зарегистрировано уменьшение на $5 \%$ численности больных активным туберкулезом в сравнении с прошлым годом, т. е. с 23745 до 22596 чел. Это произошло на фоне снижения на $15 \%$ общей инфекционной заболеваемости по итогам 2016 г.

Число больных с впервые установленным диагнозом "туберкулез», содержащихся под стражей или отбывающих наказание 
в виде лишения свободы, сократилось на 13,8 \%, т. е. с 3943 до 3399 чел. Показатель заболеваемости туберкулезом в перерасчете на 100 тыс. чел. уменьшился на 13,4\% - с 741 до 642 случаев на 100 тыс. чел.

Для пенитенциарных ведомств всех стран актуальным является показатель числа ВИЧ-инфицированных осужденных. Количество больных ВИЧ-инфекцией, содержащихся в российских учреждениях УИС, увеличилось на 3,2 \% и составило 64,5 тыс. чел. В прошлом году аналогичный показатель был равен 62,5 тыс. чел. Однако число больных, получающих высокоактивную антиретровирусную терапию, возросло на 29,1 \% (с 14841 в 2015 г. до 19162 в 2016 г.).

В 2016 г. в связи с увеличением сроков поставки антиретровирусных препаратов Минздравом России медико-санитарная служба ФСИН России предприняла ряд необходимых мер по стабилизации ситуации с лекарственным обеспечением исправительных учреждений препаратами высокоактивной антиретровирусной терапии, благодаря чему удалось обеспечить непрерывность лечения ВИЧ-инфицированных заключенных до поставки препаратов Минздравом.

Показатель смертности от ВИЧ-инфекции составил 170,9 случая на 100 тыс. чел. В 2016 г. умерло 1092 заключенных, что ниже показателя прошлого года на 7,0 \% (1 193 заключенных; 183,8 случая на 100 тыс. чел.).

Планомерная работа по совершенствованию нормативной базы, а также изменение судебной практики [1; 2] привели к тому, что увеличился процент освобождаемых судами от исполнения наказания лиц, страдающих тяжелыми заболеваниями. В 2016 г. из 3497 осужденных, представленных в суд для освобождения в связи с болезнью, было освобождено 1688 чел. (48,3 \%), и это на 52,8 \% больше показателя прошлого года (1 105 чел. из 3 107, что составило лишь 35,6\%).

В рамках реализации положений Концепции развития УИС было подготовлено распоряжение ФСИН России от 30 декабря
2016 г. № 190-р, утверждающее комплексную ведомственную программу повышения мотивации здорового образа жизни подозреваемых, обвиняемых и осужденных ${ }^{2}$.

Ранее постановлением Правительства Российской Федерации от 19 мая 2017 г. № 598 был утвержден предложенный Перечень заболеваний, препятствующих отбыванию наказания. С целью дальнейшего приведения деятельности медико-санитарной службы УИС в соответствие с требованиями законодательства в сфрере здравоохранения был разработан и направлен в Министерство юстиции Российской Федерации проект приказа «Об утверждении порядка организации медицинской помощи лицам, заключенным под стражу или отбывающим наказание в виде лишения свободы». В Правительство России внесен на рассмотрение проект постановления «О медицинском освидетельствовании осужденных, представляемых к освобождению от наказания в связи с болезнью» ${ }^{3}$.

Полагаем, что вступление в силу этих нормативных актов будет способствовать дальнейшему совершенствованию организации деятельности медико-санитарной службы УИС, несмотря на возможное дальнейшее сокращение бюджетных расходов на пенитенциарную систему.

2 Уголовно-исполнительный кодекс Российской Федерации от 8 янв. 1997 г. № 1-ФЗ (ред. от 3 февр. 2014 г.) // Собрание законодательства РФ. 1997. № 2. Ст. 198 ; Об учреждениях и органах, исполняющих уголовные наказания в виде лишения свободы : закон РФ от 21 июля 1993 г. № 5473-1 // Ведомости Съезда народных депутатов и Верховного Совета Российской Федерации. 1993. № 33. Ст. 1316 ; О содержании под стражей подозреваемых и обвиняемых в совершении преступлений : федер. закон от 15 июля 1995 г. № 103-Ф3 // Собрание законодательства РФ. 1995. № 29. Ст. 2759 ; О Концепции развития уголовно-исполнительной системы Российской Федерации до 2020 г. : распоряжение Правительства РФ от 14 окт. 2010 г. № 1772-р / / Там же. 2010. № 43. СТ. 5544.

${ }^{3}$ О содержании под стражей подозреваемых и обвиняемых в совершении преступлений : федер. закон от 15 июля 1995 г. № 103-ср3.

\section{СПИСОК ИСПОЛЬЗОВАННОЙ ЛИТЕРАТУРЫ}

1. Костик Е. В. Критика некоторых положений «Концепции развития уголовно-исполнительной системы Российской Федерации до 2020 года» / Е. В. Костик / / Актуальные вопросы образования и науки. - 2014. № 5-6. - С. 65-67.

2. Костик Е. В. Понятие и цели наказания / Е. В. Костик // Вестник международного Института управления. - 2014. - № 3-4 (127-128). - С. 56-58.

\section{REFERENCES}

1. Kostik E.V. Critics of Some Provisions of the «Concept of the Penitentiary System Development in the Russian Federation until 2020». Aktual'nye voprosy obrazovaniya i nauki = Topical Issues of Education and Science, 2014, no. 5-6, pp. 65-67. (In Russian). 
2. Kostik E.V. The Definition and Objectives of Punishment. Vestnik mezhdunarodnogo Instituta upravleniya $=$ Herald of the International Institute of Management, 2014, no. 3-4 (127-128), pp. 56-58. (In Russian).

\section{Информация об авторах}

Хабриев Рамил Усманович - академик РАН, доктор медицинских наук, доктор фармацевтических наук, профессор, директор, Национальный НИИ общественного здоровья им. Н. А. Семашко, 105064, г. Москва, ул. Воронцово Поле, 12, стр. 1, e-mail: institute@nriph.ru, http://orcid.org/00000003-2283-376X.

Суходолов Александр Петрович - доктор экономических наук, профессор, ректор, Байкальский государственный университет, 664003, г. Иркутск, ул. Ленина, 11, e-mail: rector@bgu.ru.

Спасенников Борис Аристархович - доктор медицинских наук, доктор юридических наук, профессор, главный научный сотрудник, НИИ Федеральной службы исполнения наказаний России, 125130, г. Москва, ул. Нарвская, 15а, e-mail: borisspasennikov@yandex.ru, http://orcid. org/0000-0002-5668-6457.

\section{Для цитирования}

Хабриев Р. У. О результатах экономической оптимизации деятельности медицинской службы ФСИН России / Р. У. Хабриев, А. П. Суходолов, Б. А. Спасенников // Известия Байкальского государственного университета. - 2017. - Т. 27, № 4. - C. 455-458. - DOI: $10.17150 / 2500-$ $2759.2017 .27(4) \cdot 455-458$

\section{Authors}

Ramil U. Khabriev - Academician of the Russian Academy of Sciences, Doctor of Medical Science, Doctor of Pharmacy, Professor, Director of the N. A. Semashko National Research Institute for Public Health, 12-1 Vorontsovo Pole St., 105064, Moscow, Russian Federation, e-mail: institute@nriph.ru, http: // orcid.org/0000-0003-2283-376X.

Alexander P. Sukhodolov - DSc in Economics, Professor, Rector, Baikal State University, 11 Lenin St., 664003, Irkutsk, Russian Federation, e-mail: rector@ bgu.ru.

Boris A. Spasennikov — Doctor of Medical Science, Doctor of Juridical Science, Professor, Chief Researcher of the Research Institute of the Federal Penitentiary Service, 15-A Narvskaja St., 125130, Moscow, Russian Federation, e-mail: borisspasennikov@yandex.ru, http://orcid.org/0000-0002-5668-6457.

\section{For citation}

Khabriev R. U., Sukhodolov A. P., Spasennikov B. A. On the Results of Economic Activity Optimization of the Medical Service of the Federal Penitentiary Service of Russia. Izvestiya Baykal'skogo gosudarstvennogo universiteta $=$ Bulletin of Baikal State University, 2017, vol. 27, no. 4, pp. 455-458. DOl: 10.17150/2500-2759.2017.27(4).455-458. (In Russian). 